\title{
'||||||||||||||||||||||||||||||||||||||||||||||||||||||||||||||.
}

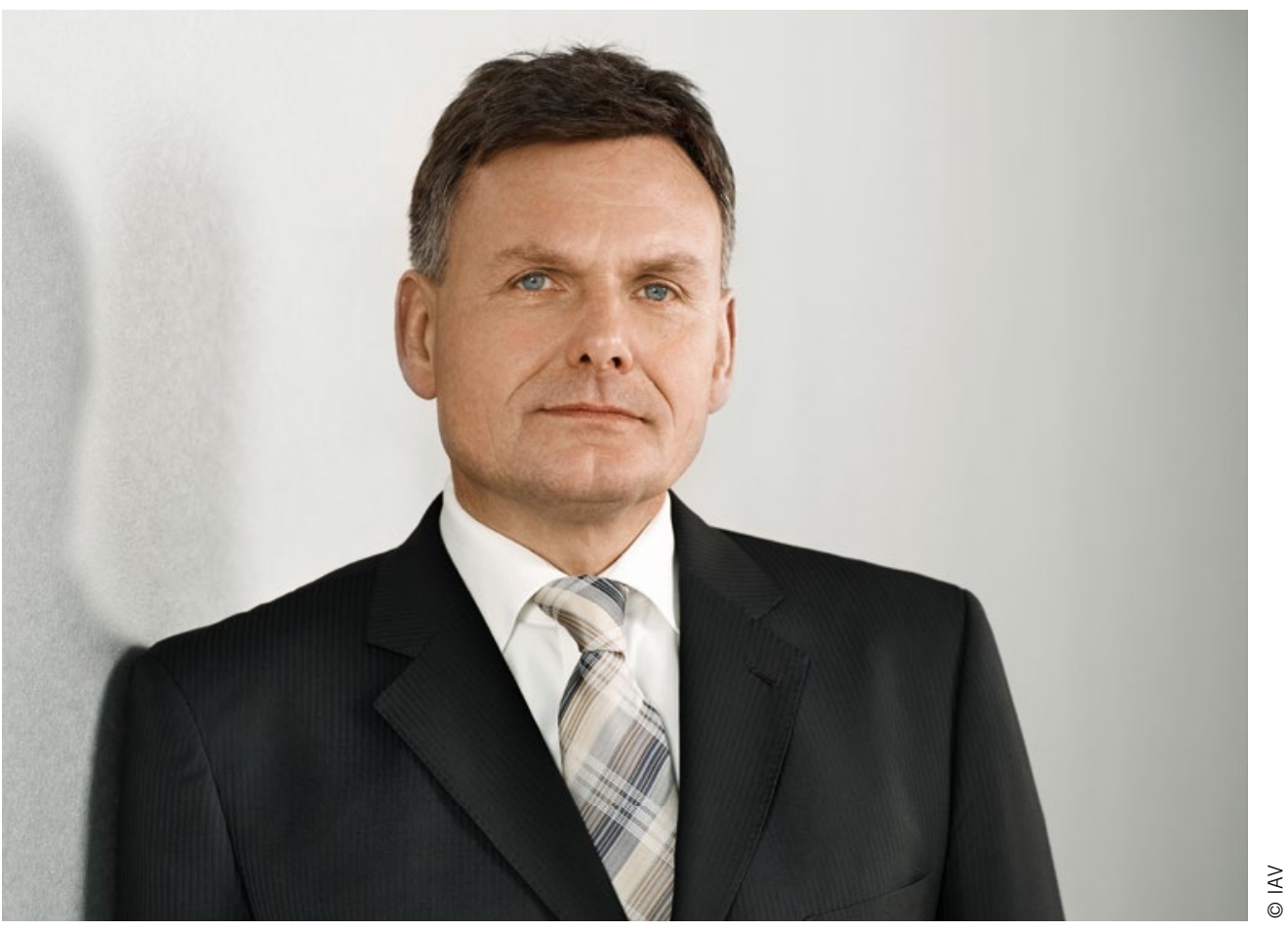

Dipl.-Ing. Kurt Blumenröder Sprecher der Geschäftsführung, IAV

\section{Auf dem Weg zum hochautomatisierten Fahren}

Heute steht für fast alle Fahrzeuge eine breite Palette an Fahrerassistenzsystemen zur Verfügung. Sie sorgen in kritischen Situationen für Stabilität, halten automatisch Abstand zum Vordermann oder unterstützen den Fahrer bei einem Spurwechsel. Grundlage sind Sensoren wie Radar, Ultraschall und Kamerasysteme, die das Umfeld überwachen und daraus ein aktuelles Lagebild erstellen. So tragen Fahrerassistenzsysteme dazu bei, den Straßenverkehr sicherer zu machen.

Der nächste Schritt zeichnet sich bereits ab: Wenn wir die Sensorsignale intelligent miteinander kombinieren, kann sich das Fahrzeug in Zukunft immer selbstständiger bewegen Stichwort „Automatisiertes Fahren“. Nach der Definition des VDA gibt es hier fünf Stufen. Die ersten drei sind „Driver Only“ (keine Unterstützung des Fahrers), „Assistiertes Fahren“ (Unterstützung bei der Längs- und Querführung) und „Teilautomatisiertes Fahren“ (vom Fahrer überwachte Längs- und Querführung). Heute haben wir diese dritte Stufe erreicht, man denke etwa an Einpark- oder Stauassistenten.

Wie die nächste vierte Stufe - das hochautomatisierte Fahren aussehen könnte, demonstrieren unsere Chemnitzer Kollegen mit einem Versuchsfahrzeug: Es kann fast ohne Eingriffe des Fahrers die $70 \mathrm{~km}$ lange Strecke von Chemnitz zum Flughafen Dresden auf der Autobahn und den angrenzenden Bundesstraßen zurücklegen. Der Prototyp hält selbstständig die Sollgeschwindigkeit ein (bis zu $130 \mathrm{~km} / \mathrm{h}$ auf der Autobahn), bleibt automatisch in der Fahrspur und überholt selbst andere Verkehrsteilnehmer - wenn der Fahrer es gestattet. Dabei nutzt er fast ausschließlich Seriensensoren, die ohnehin für die Assistenzsysteme benötigt werden.

Das Beispiel zeigt: Die Fahrerassistenzsysteme verschmelzen immer weiter, um künftig das hochautomatisierte Fahren zu ermöglichen. Die Sensorik und die Algorithmen sind vorhanden, sodass ich bis 2018 mit autonom parkenden Fahrzeugen und bis 2020 sogar mit dem hochautomatisierten Fahren auf Autobahnen rechne.

Entscheidend für neue Assistenzfunktionen und eine weitere Automatisierung in Richtung fünfter Stufe des vollautomatisierten Fahrens ist auch die Car-to-X-Kommunikation, bei der das Fahrzeug andere Verkehrsteilnehmer und die umgebende Infrastruktur als weitere Sensoren für neue Assistenzsysteme nutzt. IAV hat auch dazu ein Versuchsfahrzeug entwickelt, das einen Ampelphasenassistenten und eine Baustellenwarnung realisiert.

Technisch steht der Entwicklung zum hochautomatisierten Fahren kaum mehr etwas im Weg. Aufgabe der Industrie ist es jetzt, ihren Kunden eine klare Roadmap für weitere Funktionen zu nennen. Die Politik muss die rechtlichen Rahmenbedingungen für die neuen Assistenzsysteme setzen - Stichwort „Wiener Konvention“. Und die Gesellschaft muss sich fragen, wie sie mit den neuen technischen Möglichkeiten umgehen möchte. 